\title{
Saneamento e saúde em terras indígenas
}

\section{Sanitation and health in indigenous lands}

\author{
Reijane Pinheiro da Silva ${ }^{1}$ \\ Denise Gomes Dourado ${ }^{1}$
}

DOI: http://dx.doi.org/10.20435/tellus.v19i39.616

\begin{abstract}
Resumo: Este artigo discute a relação entre saneamento e saúde em Terras Indígenas brasileiras, problematizando os impactos do contato dos povos indígenas com a sociedade nacional. Através do levantamento bibliográfico e da observação participante em uma aldeia do Povo Akwẽ Xerente do Tocantins, constatamos que, apesar da legislação vigente e dos planos e programas de saneamento, as ações mostram-se fragmentadas. Os serviços oferecidos são insuficientes para alterar as condições inadequadas de saneamento básico e, consequentemente, de saúde, disponíveis à população indígena. $A$ baixa qualidade da água de abastecimento humano e a ausência de coleta e tratamento dos esgotos e dos resíduos sólidos estão diretamente relacionadas com doenças infecciosas e parasitárias, que permanecem como importante causa de morbimortalidade dos povos indígenas no Brasil.
\end{abstract}

Palavras-chave: saneamento básico; terras indígenas; legislação; saúde.

Abstract: This article discusses the relationship between sanitation and health in Brazilian Indigenous Lands, problematizing the impacts of indigenous peoples' contact with national society. Through the bibliographical survey and participant observation in a village of the Akwẽ Xerente People of Tocantins, we find that despite the current legislation and sanitation plans and programs, the actions are fragmented. The services offered are insufficient to alter the inadequate conditions of sanitation and, consequently, health, available to the indigenous population. The low quality of human water supply and the lack of collection and treatment of sewage and solid waste are directly related to infectious and parasitic diseases, which remain an important cause of morbidity and mortality among indigenous peoples in Brazil.

Keywords: basic sanitation; indigenous lands; legislation; health.

1 Universidade Federal do Tocantins (UFT), Palmas, Tocantins, Brasil. 


\section{INTRODUÇÃO}

De acordo com dados do último censo populacional do Instituto Brasileiro de Geografia e Estatística (IBGE), realizado em 2010, a população indígena no país é formada por 896,9 mil indivíduos, de 305 etnias, distribuídos em 505 terras indígenas (IBGE, 2012). Em 2008, existiam cadastrados no Sistema de Informação da Atenção à Saúde Indígena (SIASI) 538.154 indígenas, de 210 povos, residentes em 4.413 aldeias, distribuídas em 615 terras indígenas, presentes em 432 municípios (FUNDAÇÃO NACIONAL DE SAÚDE [FUNASA], 2009). As diferenças entre os dados divulgados pelo IBGE e pela FUNASA se devem ao fato de que o primeiro utilizou a autoidentificação, enquanto o segundo considerou apenas a população cadastrada no SIASI. Em relação ao número de terras indígenas, ele é maior nos dados da FUNASA, pois foram contabilizadas as terras já regularizadas e aquelas que ainda estão em estudo. Essa população, podemos afirmar, é sobrevivente de um violento processo de colonização econômica e cultural, que permanece atingindo seus modos de vida e sua relação com os territórios tradicionalmente ocupados. Um exemplo desse impacto é o imperativo da ocupação sedentária dado pela demarcação das terras. São constantes no cotidiano dos povos indígenas do Brasil contemporâneo a tensão social e a vulnerabilidade (SIMÕES et al., 2015). Comumente, estas populações vivem em condições de exclusão social, com atendimento precário ou desprovidas de serviços de saneamento básico e atenção à saúde (ESCOBAR-PARDO et al., 2010).

A partir do contato com não índios, os grupos indígenas sofreram transformações em seus modos de vida, as quais afetam suas práticas alimentares, condições de vida e saúde (GARNELO; PONTES, 2012). Observa-se a tendência de sedentarização desses grupos, o que resulta na redução da oferta de recursos naturais no local e na contaminação gradativa destes (GARNELO; PONTES, 2012). As diferenças culturais e as dificuldades de lidar com o novo modo de ocupação, além da adoção de práticas de consumo comuns aos não indígenas, favorecem a ocorrência de infestações parasitárias, diarreia e desnutrição nesta população.

É amplamente reconhecido que o saneamento básico constitui um importante meio de prevenir doenças. Sendo assim, "não basta apenas a existência do espaço territorial, mas também a sua qualidade deve ser preservada para garantir a saúde da população que ali habita e usufrui" (TOLEDO, 2006, p. 51). No entan- 
to, é preciso que a infraestrutura para promoção de saneamento básico, assim como os processos de educação em saúde e educação ambiental, contemple as particularidades locais (GIATTI; CUTOLO, 2012 ; GOMES, 2013; PENA; HELLER, 2008; TOLEDO, 2006), o que se torna ainda mais complexo devido à diversidade de povos indígenas no Brasil (BENEVIDES; PORTILLO; NASCIMENTO, 2014). Se nas populações envolventes ainda existe um deficit de atendimento com serviços de saneamento básico, nas populações tradicionais esse deficit é ainda maior, apesar de a legislação brasileira prever condições adequadas de salubridade ambiental a estas populações, inclusive com soluções compatíveis com suas características socioculturais.

Diante disso, este estudo teve como objetivo explanar a respeito da legislação para a promoção de saneamento em áreas indígenas do Brasil e discutir a respeito da realidade observada em algumas dessas áreas. No Tocantins, apontamos como realidade que reflete esse processo o povo Akwẽ Xerente, que vive em duas Terras Indígenas localizadas a $80 \mathrm{~km}$ da capital do estado, Palmas. Avaliamos alguns dos impactos do sedentarismo, resultado da demarcação das terras, bem como a substituição de práticas alimentares sustentadas no plantio por hábitos de consumo que geram resíduos sólidos e contribuem para a contaminação do solo e das águas.

\section{LEGISLAÇÃO A RESPEITO DE SANEAMENTO EM ÁREAS INDÍGENAS NO BRASIL}

O Serviço de Unidades Sanitárias Aéreas (SUSA), criado em 1950 pelo Ministério da Saúde, foi o primeiro órgão voltado para desenvolver ações básicas de saúde junto à população rural que habitava áreas de difícil acesso, incluindo a população indígena, mas em 1967, com a criação da Fundação Nacional do Índio (FUNAI), a responsabilidade sobre os indígenas foi atribuída ao órgão recém-criado (SERAFIM, 2004 apud TOLEDO, 2006). A partir de debates realizados na I Conferência Nacional de Proteção à Saúde do Índio, em 1986, elaborou-se uma proposta de atenção à saúde dos povos indígenas, tendo como estratégia a criação de Distritos Sanitários Especiais Indígenas (DSEIs) (TOLEDO, 2006). Em 1988, a Constituição Federal reconheceu os direitos dos povos originários às suas terras, a políticas sociais diferenciadas e adequadas às suas especificidades culturais, à 
autorrepresentação jurídico-política e à preservação de suas línguas e culturas (GARNELO; PONTES, 2012). Em 1991, a atenção à saúde indígena foi transferida, pelo Decreto n. 23, da FUNAI à FUNASA, órgão do Ministério da Saúde (BRASIL, 1991). Neste mesmo ano, a Resolução do Conselho Nacional de Saúde no 11 instituiu a Comissão Intersetorial de Saúde do Índio (CISI), cujo objetivo era:

Assessorar o Conselho Nacional de Saúde na elaboração de princípios e diretrizes das políticas no campo da saúde indígena, assim como no acompanhamento da saúde dos povos indígenas por meio da articulação Intersetorial com órgãos dos governos e com a sociedade civil organizada. (ALTINI et al., 2013, p. 9).

Em 1994, o Decreto n. 1.141 constituiu a Comissão Intersetorial de Saúde (CIS), sob a coordenação da FUNAI (BRASIL, 1994). A CIS tinha como competências: definir os objetivos dos programas e projetos a serem executados; analisar e aprovar os programas e projetos propostos; e estabelecer prioridade para otimizar o uso dos recursos (BRASIL, 1994). A CIS aprovou o Modelo de Atenção Integral à Saúde do Índio, que atribuiu à FUNAI a responsabilidade sobre a recuperação da saúde dos índios doentes e a prevenção à FUNASA (FUNASA, 2002). Na prática, este Decreto devolveu a coordenação das ações de saúde à FUNAI. Já em agosto de 1999 foi instituído o Decreto n. 3.156, que, entre outras coisas, dispõe sobre as condições para a prestação de assistência à saúde dos povos indígenas, no âmbito do Sistema Único de Saúde (SUS), pelo Ministério da Saúde, e altera dispositivos dos Decretos n. 564/1992 e n. 1.141/1994 (BRASIL, 1999a). A partir desse Decreto, as políticas e diretrizes para a promoção, prevenção e recuperação da saúde do índio seriam executadas pela FUNASA, à FUNAI caberia apenas comunicar à FUNASA a existência de grupos indígenas isolados (BRASIL, 1999a).

Ainda em 1999, a Lei Federal n. 9.836 instituiu o Subsistema de Atenção à Saúde Indígena, componente do SUS, e criou oficialmente os DSEIS (BRASIL, 1999b), que foram divididos por área territorial, tendo como base a ocupação geográfica das comunidades indígenas, e são responsáveis pelo conjunto de ações que têm por objetivo promover a atenção à saúde e as práticas sanitárias adequadas, estimulando também o controle social. Com a reestruturação da FUNASA, em 2000 foi criado o Departamento de Saúde Indígena (DESAI) e, a partir de então, a FUNASA assumiu definitivamente a saúde dos povos indígenas e redefiniu os DSEIs de acordo com a denominação, vinculação administrativa, 
jurisdição territorial, sede, população, etnias e casa do índio (BORGES; OLIVEIRA, 20016). Em janeiro de 2002, a Portaria n. 254 aprovou a Política Nacional de Atenção à Saúde dos Povos Indígenas e, entre as suas diretrizes, estão aquelas que envolvem a promoção do saneamento básico em terras indígenas (GOMES, 2013). Entre os objetivos da Lei Federal n. 11.445/2007, que definiu a Política Federal de Saneamento Básico, está o de "proporcionar condições adequadas de salubridade ambiental aos povos indígenas e outras populações tradicionais, com soluções compatíveis com suas características socioculturais". Segundo a mesma lei, o Plano Nacional de Saneamento Básico (PLANSAB), entre outras coisas, deve "tratar especificamente das ações da União relativas ao saneamento básico nas áreas indígenas [...]" (BRASIL, 2007). Em seu estudo, Gomes (2013) destaca o fato de que o saneamento básico ao longo das décadas desenvolveu-se de forma fragmentada e pulverizada em várias instituições, sem uma política definida até a promulgação da Lei Federal n. 11.445/2007.

Em 2010, foi criada a Secretaria Especial de Saúde Indígena (SESAI), um subsistema do Sistema Único de Saúde (SUS), em substituição à FUNASA no atendimento à saúde indígena. A SESAI oferece atendimento com base nos DSEls e é também responsável pelas informações do Sistema de Informação de Atenção à Saúde Indígena (SIASI).

O Decreto n. 7.336/2010 aprovou a estrutura regimental do Ministério da Saúde e, com a criação da SESAI, a gestão do Subsistema de Atenção à Saúde Indígena ficou totalmente sob a responsabilidade deste Ministério (BENEVIDES; PORTILLO; NASCIMENTO, 2014). Em 2013, uma nova estrutura regimental do Ministério da Saúde foi aprovada pelo Decreto n. 8.065, mas o responsável pela gestão do Subsistema de Atenção à Saúde Indígena continuou sendo o Ministério da Saúde. Aprovado em 2013, o PLANSAB atribuiu à FUNASA a competência de atender, sob a coordenação do Ministério da Saúde, as aldeias indígenas (BRASIL, 2013). Entre os programas propostos está o Programa Nacional de Saneamento Rural, que visa atender a população rural e as comunidades tradicionais com medidas de saneamento básico, provimento de banheiros e unidades hidrossanitárias domiciliares e educação ambiental para o saneamento. O Ministério da Saúde é o responsável pela coordenação do Programa, para o qual são estimados R\$22,7 bilhões para investimentos nos próximos 20 anos (BRASIL, 2013). 
A Lei Federal n. 13.249/2016 instituiu o Plano Plurianual da União para o período de 2016 a 2019. Dentre os seus Programas Temáticos, considerando o tema em debate, destacam-se os programas "Proteção e Promoção dos Direitos dos Povos Indígenas" e "Saneamento Básico", o primeiro sob responsabilidade dos Ministérios da Justiça, da Saúde e do Desenvolvimento Agrário, e o segundo sob responsabilidade dos Ministérios das Cidades e da Saúde (BRASIL, 2016).

Conforme visto, ao longo dos anos, a responsabilidade pela saúde e provisão de infraestrutura em áreas indígenas por vezes foi passada de um ministério a outro ou compartilhada entre eles, destacando-se os Ministérios da Saúde e da Justiça. Atualmente, a gestão do Subsistema de Atenção à Saúde Indígena está sob a responsabilidade do Ministério da Saúde. Em relação às instituições responsáveis pelo atendimento das necessidades de saúde e saneamento dos indígenas, Pena e Heller (2008) apontam para deficiências da estrutura burocrático-administrativa, que se apresentava fragmentada. Segundo estes autores, não há clareza quanto à definição de competências e responsabilidades no planejamento, execução, fiscalização e avaliação dos serviços de saúde.

\section{CONDIÇÕES DE SAÚDE E SANEAMENTO EM ÁREAS INDÍGENAS NO BRASIL}

O Brasil não possui um banco de dados fidedignos e de fácil acesso que forneça informações sobre cobertura e qualidade de serviços de saneamento básico e saúde indígena, os dados disponíveis são parciais, gerados pela FUNAI, FUNASA e organizações não governamentais, missões religiosas e instituições acadêmicas (Simões et al., 2015). Em 2000, foi criado o SIASI, com objetivo de coletar informações e construir indicadores para subsidiar o planejamento, a organização e as avaliações da prestação dos serviços de saúde e evolução da qualidade de vida nas aldeias indígenas (GOMES, 2013). A partir de então, algumas informações demográficas e de morbidade passaram a ser coletadas de forma mais abrangente e com certa regularidade, o que tem contribuído para um melhor dimensionamento do problema (GARNELO; PONTES, 2012). No entanto, o SIASI não disponibiliza as informações produzidas para acesso público.

Diante disso, a realização do I Inquérito Nacional de Saúde e Nutrição dos Povos Indígenas, no período de 2008 a 2009, constituiu um marco da saúde coletiva brasileira (COIMBRA JR., 2014). O I Inquérito foi realizado pela FUNASA 
em parceria com a Associação Brasileira de Saúde Coletiva (ABRASCO). Foram visitadas 113 aldeias, entrevistadas 6.605 mulheres e 6.583 crianças (FUNASA, 2010). É importante mencionar que o CENSO demográfico de 2010 do IBGE investigou características gerais dos indígenas, o que também tem contribuído para os estudos e as discussões.

Alguns resultados do Inquérito supracitado: no Brasil, 19\% dos domicílios indígenas tinham banheiro dentro de casa e 30,6\% dos respondentes disseram defecar fora dos locais apropriados; dos 19\% que dispunham de banheiro dentro de casa, 36,5\% encaminhavam os esgotos para rede de esgotamento sanitário ou fluvial ou fossa séptica e 63,5\% para fossa rudimentar, vala, rio, lago ou mar; a maioria utilizava água sem tratamento e de fontes locais; os resíduos sólidos de 79\% dos domicílios eram enterrados, queimados ou jogados no entorno da aldeia; nos 12 meses anteriores às entrevistas, foram constatadas elevadas prevalências de hospitalização por diarreia $(37,2 \%)$ e infecção respiratória aguda $(47,6 \%)$ e 23,6\% das crianças tiveram diarreia na semana da entrevista; os coeficientes de mortalidade infantil chegavam a 97 óbitos em menores de um ano por 1.000 nascidos vivos, como observado entre os Xavante (COIMBRA JR., 2014).

Em 2003, Pena e Heller (2008) investigaram a situação do abastecimento de água e do esgotamento sanitário, o quadro da saúde e a associação ecológica entre a mudança ou a prevalência do nível de exposição à carência dos serviços e os indicadores de saúde na população infantil indígena Xakriabá, Minas Gerais. Na época, 50,2\% das moradias eram atendidas por rede de abastecimento de água e 3,9\% da população tinha água clorada; dos 108 pontos amostrais onde foram realizadas análises da água utilizada para beber, apenas 24 apresentaram ausência de coliformes totais e Escherichia coli e, entre as amostras coletadas nas moradias cuja água era oriunda de poços tubulares profundos, em 83,3\% a água era imprópria para o consumo humano.

Pena e Heller (2008) afirmam que, apesar da atuação da FUNASA, por meio do DSEI, os serviços ofertados não se mostraram capazes de contornar a situação frágil da saúde indígena no local e os serviços de saneamento são necessários, porém não são suficientes para promover a melhoria da saúde em Terras Indígenas, pois é fundamental que sejam consideradas as peculiaridades locais para que as práticas educativas alcancem os sujeitos de forma a garantir melhorias na saúde 
destes indivíduos. Dias Júnior et al. (2013), em 2007, realizaram um estudo cujo objetivo foi verificar a prevalência de parasitoses intestinais e o estado nutricional entre os indígenas residentes na Terra Indígena Caxixó, região centro-oeste de Minas Gerais. Foram entrevistadas 58 pessoas e, através de exames parasitológicos, constatou-se que $22,8 \%$ da população Caxixó estava infectada com algum tipo de parasitose intestinal (DIAS JÚNIOR et al., 2013). Giatti e Cutolo (2012) buscaram identificar aspectos atuais da situação de acesso à água para consumo humano na Amazônia Brasileira, incluindo algumas comunidades indígenas.

Um dos estudos de caso foi o da sede do distrito de lauaretê, situado no Amazonas, que abriga múltiplas etnias indígenas e possuía cerca de 2.700 habitantes em 2005, distribuídos em 10 vilas, onde inexistiam rede de abastecimento de água e rede de coleta e tratamento de esgotos (GIATTI; CUTOLO, 2012). Foram analisadas 65 amostras de água de abastecimento, das quais 89,2\% apresentaram contaminação por material fecal. Não havia nenhuma solução sanitariamente adequada para os resíduos sólidos e as práticas sanitárias dos indígenas eram destoantes em relação ao conhecimento que possuíam sobre o assunto, pois, embora os indígenas tivessem conhecimentos de conceitos biomédicos, estes passavam por uma ressignificação em que prevalecia a lógica do pensamento mítico (GIATTI; CUTOLO, 2012).

Outro estudo de caso apresentado por Giatti e Cutolo (2012) foi o do município de São Gabriel da Cachoeira, também no Estado do Amazonas e com grande parte de sua área integrante de um conjunto de terras indígenas, o qual contava em 2003 com uma população de aproximadamente 18.000 habitantes, dos quais $80 \%$ eram indígenas (FOIRN, 2003 apud GIATTI; CUTOLO, 2012). O município estudado possuía dois subsistemas de abastecimento público de água, ambos sem nenhum tratamento da água. Em um deles, a água era captada diretamente do rio Negro e distribuída para a população, cobrando-se um valor fixo mensal por ligação. Já o outro era formado por sistemas isolados de distribuição de água captada de poços em perímetro urbano, armazenada em caixas d'água e distribuída em torneiras públicas. Na área urbana, não existiam sistemas de esgotamento sanitário e, nas comunidades indígenas, não havia instalações sanitárias e registravam-se práticas sanitárias indígenas tradicionais, como captação de água na natureza e a defecação em áreas isoladas (GIATTI; CUTOLO, 2012). 
Em 2011, Mazzeti (2015) avaliou o estado nutricional, o perfil sociodemográfico e econômico, o saneamento básico e a forma de obtenção de alimentos dos indígenas das cinco aldeias Pataxó em Minas Gerais. Mais de $80 \%$ dos domicílios possuíam latrina/sanitário e mais da metade possuía fossas sépticas. Metade dos domicílios possuía coleta de resíduos sólidos e 35,7\% recebiam a água para consumo humano via torneira, sendo o restante proveniente diretamente de poços, minas ou cacimbas. Dentre aqueles que obtinham água a partir de torneiras, a maioria usava água sem tratamento e, em $60 \%$ dos domicílios, a água era filtrada antes de beber (MAZZETI, 2015).

O estudo de Escobar-Pardo et al. (2010) teve como objetivo determinar as taxas de prevalência de infestação parasitária, em 2007 e 2008, nas crianças de 2 a 9 anos de seis aldeias do Parque Indígena do Xingu, situadas nas regiões do Médio e Baixo Xingu. Em 2007, foram coletadas amostras fecais de 202 crianças e o exame parasitológico resultou positivo em 97,5\% dos casos; já em 2008 foram coletadas amostras de 102 crianças, das quais $96,1 \%$ foram positivas para a presença de parasitas. Segundo os autores, a parasitose é endêmica nas comunidades estudadas e as crianças destes locais apresentam alto risco de contrair a infestação ou tornarem-se infestadas.

Ainda de acordo com Escobar-Pardo et al. (2010, p. 495),

[...] os fatores epidemiológicos da infeç̧ão em comunidades indígenas são similares aos de outras populações de baixo nível socioeconômico, caracterizadas por altas taxas de parasitoses na infância. Os fatores de risco associados às altas prevalências de parasitoses, como ausência de saneamento básico, ingestão de água não tratada e determinados hábitos de higiene pessoal, culturais e dietéticos, como comer com as mãos, defecar no ambiente, ausência de métodos de conservação dos alimentos, não usar calçados, dentre outros, são variáveis frequentemente observadas nas comunidades indígenas.

Toledo (2006), por sua vez, identificou problemas sanitários e socioambientais que interferiam diretamente na saúde e qualidade de vida no distrito de lauaretê - Amazonas, também estudado por Giatti e Cutolo (2012). lauaretê tinha uma população de 2.683 habitantes, de 13 etnias diferentes. A autora constatou práticas tradicionais incompatíveis com a atual elevada concentração populacional local, o que expunha os indígenas a riscos epidemiológicos. 
Toledo (2006) constatou que os indígenas se mostraram preocupados com a poluição do solo e da água e desejavam melhorias sanitárias e, assim como Giatti e Cutolo (2012), reconhece que a população local sabe as situações de causa e efeito de doenças evitáveis por meio do saneamento e práticas saudáveis, mas que o conhecimento ainda não havia se transformado em práticas.

Em 2009, Simões et al. (2015) estudou as condições ambientais e o quadro de infecção parasitária dos indígenas Xukuru-Kariri residentes em Caldas, Minas Gerais. A água era proveniente de um único poço artesiano e nem todos os domicílios possuíam água canalizada, 76,9\% das amostras de água do sistema de abastecimento foram positivas para coliformes totais e $66,7 \%$ dos exames parasitológicos foram positivos para a presença de parasitas. Os esgotos eram canalizados até uma fossa ou lançados a céu aberto. Apenas uma residência não possuía banheiro, mas alguns entrevistados relataram defecar na natureza. Havia coleta semanal de resíduos sólidos, mas parte deles era queimada ou jogada nos quintais.

Com exceção do estudo realizado por Mazzeti (2015), que apresenta resultados distante do ideal, embora relativamente melhores, os resultados das pesquisas supracitadas apontam para uma enorme deficiência quanto à infraestrutura para promoção de saneamento básico. No entanto, a implantação dessa infraestrutura deve considerar as características geográficas, as necessidades locais, os hábitos e as questões culturais de cada povo, além de realizar processos de educação em saúde e educação ambiental que contemplem essas particularidades (TOLEDO, 2006).

O I Inquérito Nacional de Saúde e Nutrição dos Povos Indígenas indicou que a maioria da água utilizada para beber não possui tratamento, o que também foi constatado por Pena e Heller (2008), Giatti e Cutolo (2012) e Mazzeti (2015). Estudos como o de Pena e Heller (2008), Giatti e Cutolo (2012) e Simões et al. (2015) indicaram que a água consumida é imprópria para tal.

Segundo Escobar-Pardo et al. (2010), a Organização Pan-Americana de Saúde revelou que as geo-helmintoses são altamente frequentes na América Latina, com prevalência estimada de 30\%, alcançando 50\% em comunidades vulneráveis e até $95 \%$ em algumas tribos indígenas. Estes autores realizaram exames parasitológicos em crianças indígenas de aldeias do Parque Indígena Xingu, em 2007 e 2008, e encontraram prevalências de, respectivamente, 97,5\% e 96,1\%. 
Entre os anos de 1998 e 2002, o coeficiente de mortalidade infantil entre os indígenas brasileiros diminuiu, em média, 10,6\% ao ano, apresentando em 1998 e em 2002, respectivamente, valores de 96,8 e 55,7 óbitos por 1.000 nascidos vivos (TOLEDO, 2006). Apesar da redução, o valor ainda é considerado de alto risco, segundo a Organização Mundial de Saúde (OMS), que define como de alto grau de risco à vida os coeficientes de mortalidade infantil acima de 50 óbitos por 1.000 nascidos vivos (GOMES, 2013). No entanto, Mazzeti (2015) chama atenção para o fato de que o coeficiente de mortalidade infantil entre os indígenas tem grande variação entre as diferentes etnias devido à heterogeneidade das condições de vida entre os grupos.

\section{OS AKWẼ XERENTE DO TOCANTINS E A NOVA REALIDADE AMBIENTAL}

Como resultado de um projeto de pesquisa e extensão desenvolvido nas Aldeias Porteira e Funil, do povo Akwẽ Xerente, entre 2013 e 2015, apresentamos algumas observações relativas às condições sanitárias das aldeias citadas, associadas às transformações sociais e culturais, bem como aos projetos de desenvolvimento implementados no entorno das TIs. Através da observação participante, identificamos uma realidade sanitária muito próxima das que foram apresentadas anteriormente. Ressaltamos que é preciso relacionar essa realidade ao contexto de transformações econômicas que se intensificaram depois da criação do estado do Tocantins, por decreto, em 1988.

Os Xerente que se autodenominam Akwẽ e são classificados na etnologia como Jê Centrais vivem no município de Tocantínia a 76 km de Palmas, TO, nas TIs Funil e Xerente, entre o Rio Tocantins, margem esquerda, e Rio Sono, margem direita. São contabilizadas 68 aldeias, que têm seis postos de saúde e 3.350 habitantes, sendo 1.689 (50,42\%) do sexo masculino e 1.661 (49,58\%) do sexo feminino. Em sua organização, os Xerente se representam na existência de duas metades exogâmicas - Dói (Sol) e Wahirê (Lua), em que os clãs representantes da metade Dói são os Kuzatdekwa (donos do fogo), Kbazitdekwa (donos do algodão), e Kritotdekwa (donos do jogo com a batata assada ou donos da borracha); quanto à metade Wahirê, estão inclusos os clãs Krozake, Kreprehi e os Wahiretdekwa. A relação entre os clãs envolve regras sociais com direitos e deveres recíprocos. Cada clã tem um conjunto de nomes próprios que são passados de pai para filho, 
de avô paterno para neto ou sobrinho-neto. Outro fator que possibilita distinguir as duas metades é a pintura corporal, já que os Wahirê utilizam traços verticais, e os Dói, círculos.

Os Akwẽ Xerente praticavam um seminomadismo, movimentando-se em um amplo espaço geográfico que corresponde ao que hoje é parte dos estados de Goiás e do Tocantins. Com vistas a permitir "o descanso da terra" ou motivados pelo faccionismo e pelas disputas clânicas, evitavam o sedentarismo e consequentemente os impactos que hoje podem ser facilmente observados, poupando o solo dos danos causados por uma permanência sedentária. Marcados, como a maioria dos Povos Indígenas brasileiros, pela pressão sobre seus territórios tradicionais, a luta pela demarcação das atuais terras foi fundamental para a sobrevivência física e cultural dos Akwẽ. Essa inquestionável conquista, no entanto, impôs a eles a necessidade do sedentarismo, impactando o solo, as águas e todos os recursos naturais disponíveis.

Somam-se a essa nova realidade as transformações nos hábitos de consumo, que passaram a gerar uma significativa quantidade de resíduos sólidos, dispensados no entorno das aldeias. As roças de coivara, também conhecidas por roças de toco, foram, por muito tempo, a principal estratégia de produção de alimentos pelos Akwẽ Xerente. Relatos históricos apontam que na primeira metade do século XIX, quando foram sistematicamente atacados pelos poderes constituídos e pelos moradores das cidades do entorno do seu território tradicional, era comum os soldados invadirem aldeias, nelas permanecendo por dias, alimentados pelas roças dos Akwẽ, como cita Giraldin (2002, p. 119).

Reunidos todos na foz do rio Sono [...], os 271 praças atacaram uma aldeia à margem esquerda do Tocantins [...] sendo os 271 praças alimentados com a produção das roças dos Xerente, tamanha era a área plantada, resolveu-se abandonar a aldeia, não sem antes destruir o restante das roças.

Depois da criação do Tocantins é possível identificar um relativo abandono do plantio de roças pelos Akwẽ. Podemos citar inúmeros fatores associados, entre eles a pressão que as TIs sofrem por causa dos projetos de desenvolvimento em seu entorno. Entre estes se destacam a produção extensiva de grãos junto da construção de usinas hidrelétricas (UHEs). A construção da UHE de Lajeado, a 70 km de Palmas, afetou diretamente as TIs Funil e Xerente, comprometendo 
a prática tradicional das "roças de vazante". Aproveitando o movimento natural do Rio Tocantins, os Akwẽ plantavam às suas margens no período de estiagem, mantendo relativa segurança alimentar com as colheitas sazonais. Com a construção da UHE no Rio Tocantins, o movimento do Rio passou a ser controlado artificialmente, impedindo o processo natural que permitia o plantio nas chamadas vazantes. A diminuição dos peixes, que antes completavam a dieta Akwẽ, é outro impacto apontado pelos moradores das aldeias às margens do rio Tocantins. Além das hidrelétricas já implantadas na bacia do rio Tocantins, a Agencia Nacional de Energia Elétrica (ANEEL) informa que estão previstas para o rio Tocantins e seus tributários uma série de empreendimentos. Somente para o rio do Sono, que define o limite nordeste da TI Xerente, estão previstas seis hidrelétricas, sendo elas: Pequena Central Hidrelétrica (PCH) Brejão Jusante e as UHEs Cachoeira da Velha, Monte Santo, Ponte Nova, Rio Sono Baixo e Vermelho (BRASIL, 2016).

Observamos ainda que o plantio em roças de coivara, que usam o fogo para provocar a fertilização do solo, é uma prática condenada pelos órgãos ambientais. Muitos Akwẽ afirmam que, para inibir a prática da coivara, chamada por eles de "roça de toco", o governo do estado do Tocantins prometeu" apoio para mecanizar o plantio nas Terras Indígenas, mas isso não acontece de forma suficiente e planejada. Alguns tratores doados pelo estado, por exemplo, nunca receberam manutenção, impedindo a continuidade dos projetos de mecanização.

O contexto apresentado causou grave insegurança alimentar entre os Akwẽ. Além dos cargos públicos, entre eles o de agente indígena de saúde, agente indígena de saneamento e professor, destinados àqueles que tiveram acesso mínimo à educação, o artesanato tradicional em fibra de buriti e capim dourado se constitui como a principal fonte de renda da maioria. O programa Bolsa Família (PBF) tem ampla cobertura entre as famílias Akwẽ, permitindo a sustentação, ainda que precária, das necessidades mais básicas das famílias. Em 2014, o cadastro único apontou que, entre as 730 famílias indígenas cadastradas, 637 foram beneficiadas pelo programa.

Com o Bolsa Família ou o salário, as famílias compram alimentos na cidade de Tocantínia, garantindo a movimentação do comércio local. Esse processo de transformação dos Akwẽ em consumidores se iniciou, sem dúvida, com os pri- 
meiros contatos com a sociedade nacional, mas se intensificou diante do contexto apresentado. Hoje é possível afirmar que boa parte da alimentação Akwẽ vem de Tocantínia. Em pesquisa sobre as mudanças de hábitos alimentares, constatou-se que arroz, feijão, açúcar, café, sal e farinha, bolachas e refrigerantes são os principais alimentos consumidos pelas famílias (ROCHA; SILVA; NASCIMENTO, 2016). Em termos de impactos ambientais, de imediato é possível apontar que a presença de resíduos sólidos tem aumentado significativamente em paralelo à mudança de hábitos alimentares. Embalagens plásticas, latas, caixas de papeIão, garrafas de vidro e garrafas PET se acumulam nas aldeias e nas margens dos córregos e das nascentes próximas. Em 2013, a prefeitura de Tocantínia, TO, em acordo com os indígenas, comprometeu-se a coletar o lixo quinzenalmente. 0 acordo previa que os Akwẽ deveriam acondicionar os resíduos e depositá-los em uma tela suspensa do solo, até a coleta. O não cumprimento do acordo por parte da prefeitura desmotivou-os a manterem as telas e o lixo voltou a ser dispensado dentro da área, enterrado ou queimado.

A estrutura das aldeias conta com um poço artesiano e uma caixa de água. As casas têm banheiros individuais, instalados no lado externo. Os banheiros contêm pia, chuveiro e vaso sanitário. Não há tratamento de dejetos e muitos banheiros precisam de reforma, alguns estão interditados para uso. Os dejetos são enviados para fossas sépticas, que nem sempre recebem a manutenção adequada. Em um esforço para diminuir as doenças parasitárias, a SESAI, através do DSEI TO, distribuiu filtros de barros para todas as famílias indígenas das TIs Xerente em 2015. Observou-se, no entanto, que essa distribuição não foi acompanhada de uma discussão profunda e sistemática sobre a função e importância do filtro, o que fez com que muitas famílias dessem outras destinações a ele. Convém ressaltar que seria fundamental um intenso debate comunitário sobre as causas das doenças parasitárias, através de ações dialógicas que valorizassem e respeitassem a compreensão indígena relativa ao tema, antes da introdução dos filtros. $O$ agente indígena de saneamento (AISAN), contratado pelo DSEI para cuidar do abastecimento de água na aldeia, muito pouco pode fazer diante de problemas estruturais e graves como os apresentados. O abastecimento das casas se dá através de torneiras distribuídas pela aldeia, ligadas diretamente às caixas de água. 0 AISAN se ocupa de resolver problemas pontuais do abastecimento, de distribuir o 
hipoclorito de sódio para as famílias, orientando-as, junto do Agente Indígena de Saúde (AIS), sobre a importância do tratamento da água para consumo. Na contramão desses esforços, a pesquisa de campo constatou que muitas famílias das aldeias citadas, após adquirirem o refrigerador, abandonavam o uso de qualquer mecanismo de filtragem ou tratamento da água. Muitos diziam acreditar que a água refrigerada estaria livre de impurezas e, como já citamos, também resistiam ao uso do filtro de barro, bem como do hipoclorito de sódio.

A aproximação com as interpretações indígenas acerca do que poderia contaminá-los permite identificar noções êmicas referentes ao adoecimento que, por serem desconhecidas dos profissionais de saúde e de outras áreas que atuam com o povo Akwẽ, comprometem o diálogo e impedem avanços nos processos de atenção. As estratégias de educação em saúde devem ser sustentadas na escuta qualificada e atenta, considerando que a história do contato desse povo com a sociedade nacional é marcada por violência, perdas e, obviamente, desconfianças. As equipes de saúde que atendem aos Akwẽ apontam que as doenças crônicas não transmissíveis têm se destacado entre os adultos nos últimos dez anos. Entre elas, hipertensão e diabetes são os agravos mais comuns. Entre as crianças, assim como aponta o I Inquérito Nacional citado, são mais comuns as doenças parasitárias, como a verminose, as doenças respiratórias e de pele. Um dos médicos que atendem a população afirmou que há um ciclo de adoecimento infantil que não se rompe, pois as condições ambientais reproduzem as infecções, que se tornam, muitas vezes, resistentes e graves.

\section{CONCLUSÕES}

Apesar da legislação vigente e dos planos e programas previstos pelo governo, as ações mostram-se fragmentadas e os serviços oferecidos são insuficientes para alterar as condições inadequadas de saneamento básico e, consequentemente, de saúde disponíveis à população indígena. Em geral, esta população vive em condições de exclusão social, com atendimento precário ou desprovidas de serviços de saneamento básico. Foi possível observar que existe uma insuficiência de dados a respeito das condições de saúde e saneamento básico nas áreas indígenas e dificuldade de acesso às informações produzidas pelo Estado, o que dificulta a realização de estudos e diagnósticos por parte de pesquisadores independentes 
ou instituições não governamentais. No entanto, apesar dos dados insuficientes para a realização de diagnósticos mais aprofundados, é possível afirmar que a ausência de sistemas de saneamento básico está diretamente relacionada com doenças infecciosas e parasitárias, que permanecem como importante causa de morbimortalidade dos povos indígenas no Brasil, embora se reconheça que apenas a implantação da infraestrutura não seja suficiente para garantir melhorias na saúde destes indivíduos.

A demarcação dos territórios, apesar de ser uma conquista fundamental, apresenta um paradoxo, pois reconfigura muitas das relações tradicionais com a água e com a terra. O contato com a sociedade envolvente e os impactos dos projetos de desenvolvimento contribuem para o acúmulo de resíduos sólidos nas aldeias e no esgotamento ou na contaminação dos recursos naturais. Concluímos que o acesso ao território não é suficiente para promover uma qualidade de vida adequada aos indígenas, é preciso que a qualidade ambiental desses territórios esteja adequada para o estabelecimento dessas populações e, para tal, é preciso considerar as características e necessidades locais, os hábitos e especificidades culturais de cada povo.

\section{REFERÊNCIAS}

ALTINI, Eliane; RODRIGUES, Gilderlan; PADILHA, Lindomar; MORAES, Paulo Daniel; LIEBGOT, Roberto Antônio (Org.). A política de atenção à saúde indígena no Brasil: breve recuperação histórica sobre a política de assistência à saúde nas comunidades indígenas. Brasília: CIMI, 2013.

BENEVIDES, Luciana; PORTILLO, José Alberto Cordón; NASCIMENTO, Wanderson Flor do. Atenção à saúde dos povos indígenas do Brasil: das missões ao subsistema. Tempus Actas de Saúde Coletiva, Brasília, v. 8, n. 1, p. 29-39, mar. 2014.

BORGES, Juliano Luís. OLIVEIRA, Weuser Donizete de. Saúde indígena. Revista Inter Texto, V. 20, n. 2, 2016.

BRASIL. Presidência da República. Casa Civil. Lei n. 13.249, de 13 de janeiro de 2016. Institui o Plano Plurianual da União para o período de 2016 a 2019. Brasília, DF, 2016. Disponível em: http://www.planalto.gov.br/ccivil_03/_Ato2015-2018/2016/Lei/L13249. htm. Acesso em: 25 maio 2016. 
BRASIL, Ministério das Cidades. Plano Nacional de Saneamento Básico. Brasília, DF, 20 de março de 2013. Disponível em: http://www.cidades.gov.br/images/stories/ArquivosSNSA/ Arquivos_PDF/plansab_06-12-2013.pdf. Acesso em: 13 maio 2016.

BRASIL. Presidência da República Casa Civil. Lei n. 11.445, de 5 de fevereiro de 2007. Estabelece diretrizes nacionais para o saneamento básico; altera as Leis n. 6.766, de 19 de dezembro de 1979, n. 8.036, de 11 de maio de 1990, n. 8.666, de 21 de junho de 1993, n. 8.987, de 13 de fevereiro de 1995; revoga a Lei n. 6.528, de 11 de maio de 1978; e dá outras providências. Brasília, DF, 2007. Disponível em: http://www.planalto.gov.br/ ccivil_03/_ato2007-2010/2007/lei/l11445.htm. Acesso em: 8 fev. 2016.

BRASIL. Presidência da República Casa Civil. Decreto n. 3.156, 27 de agosto de 1991. Dispõe sobre as condições para a prestação de assistência à saúde dos povos indígenas, no âmbito do Sistema Único de Saúde, pelo Ministério da Saúde, altera dispositivos dos Decretos n. 564, de 8 de junho de 1992, e 1.141, de 19 de maio de 1994, e dá outras providências. Brasília, DF, 1999a. Disponível em: http://www.planalto.gov.br/ccivil_03/ decreto/D3156.htm. Acesso em 17 de maio de 2016.

BRASIL. Presidência da República Casa Civil. Lei Federal n. 9.836, de 23 de setembro de 1999. Acrescenta dispositivos à Lei n. 8080, de 19 de setembro de 1990, que "dispõe sobre as condições para a promoção, proteção e recuperação da saúde, a organização e o funcionamento dos serviços correspondentes e dá outras providências", instituindo o Subsistema de Atenção à Saúde Indígena, Brasília, DF, 1999b. Disponível em: http://www. planalto.gov.br/ccivil_03/leis/I9836.htm. Acesso em: 13 maio 2016.

BRASIL. Presidência da República Casa Civil. Decreto n. 1.141, de 19 de maio de 1994. Dispõe sobre as ações de proteção ambiental, saúde e apoio às atividades produtivas para as comunidades indígenas. Brasília, DF, 1994. Disponível em: http://www.planalto. gov.br/ccivil_03/decreto/Antigos/D1141impressao.htm. Acesso em: 18 maio 2016.

BRASIL. Presidência da República Casa Civil. Decreto n. 23, de 4 de fevereiro de 1991. Dispõe sobre as condições para a prestação de assistência à saúde das populações indígenas. Brasília, DF, 1991. Disponível em: http://www.planalto.gov.br/ccivil_03/ decreto/1990-1994/D0023.htmimpressao.htm. Acesso em: 13 maio 1991.

BRASIL. Agência Nacional de Energia Elétrica. Relatório de Acompanhamento de Empreendimentos de Geração. 2016. Disponível em: http://www.aneel.gov.br/sala-deimprensa-exibicao-2/-/asset_publisher/zXQREz8EVIZ6/content/aneel-divulga-relatoriode-acompanhamento-de-empreendimentos-de-geracao/656877?inheritRedirect=false. Acesso em: 6 jun. 2019. 
COIMBRA JR., Carlos Everaldo Álvares. Saúde e povos indígenas no Brasil: reflexões a partir do I Inquérito Nacional de Saúde e Nutrição Indígena. Cadernos de Saúde Pública, Rio de Janeiro, v. 30, n. 4, p. 855-9, abr. 2014.

DIAS JÚNIOR, Cláudio S.; OLIVEIRA, Cinthia Teixeira de; VERONA, Ana Paula de A.; PENA, João Luiz; SÍRIO, Marília Alfenas de O.; BAHIA, Maria Terezinha; MACHADO-COELHO, George Luiz L. Prevalência de parasitoses intestinais e estado nutricional, segundo sexo e idade, entre a população indígena Caxixó, Minas Gerais, Brasil. Revista Brasileira de Estudos de População, Rio de Janeiro, v. 30, n. 2, p. 595-602, jul./dez. 2013. Disponível em: http://www.scielo.br/pdf/rbepop/v30n2/13.pdf. Acesso em: 15 maio 2016.

ESCOBAR-PARDO, Mário Luis; GODOY, Anita Paula Ortiz de; MACHADO, Rodrigo Strehl; RODRIGUES, Douglas; FAGUNDES NETO, Ulysses; KAWAKAMI, Elisabete. Prevalência de parasitoses intestinais em crianças do Parque Indígena do Xingu. Jornal de Pediatria, v. 86, n. 6, p. 493-6, 2010. Disponível em: http://www.scielo.br/pdf/jped/v86n6/v86n6a08. pdf. Acesso em: 16 maio 2016.

FUNDAÇÃO NACIONAL DE SAÚDE (FUNASA). Relatório de Gestão 2008. Brasília, 2009. 81 p. Disponível em: http://www.funasa.gov.br/site/wp-content/uploads/2011/10/ relatorio_2008.pdf. Acesso em: 15 maio 2016.

FUNDAÇÃO NACIONAL DE SAÚDE (FUNASA). Política Nacional de Atenção à Saúde dos Povos Indígenas. 2. ed. Brasília, 2002. 40 p. Disponível em: http://bvsms.saude.gov.br/ bvs/publicacoes/politica_saude_indigena.pdf. Acesso em: 18 maio 2016.

GARNELO, Luiza; PONTES, Ana Lúcia (Org.). Saúde indígena: uma introdução ao tema. Brasília: MEC/Unesco, 2012.

GIATTI, Leandro Luiz; CUTOLO, Silvana Audrá. Acesso à água para consumo humano e aspectos de saúde pública na Amazônia Legal. Ambiente \& Sociedade [online], São Paulo, v. 15, n. 1, p. 93-109, jan./abr. 2012. Disponível em: http://www.scielo.br/scielo. php?pid=S1414-753X2012000100007\&script=sci_abstract\&tlng=pt. Acesso em: $20 \mathrm{de}$ novembro de 2019.

GIRALDIN, Odair (Org.). A (trans)-formação histórica do Tocantins. Goiânia: UFG; Palmas: Unitins, 2002.

GOMES, Solange Lima. Resíduos sólidos dos serviços de saúde em terras indígenas: o caso do distrito sanitário especial indígena Médio Rio Purus, Amazonas. 2013. Dissertação (Mestrado em Desenvolvimento Sustentável) - Universidade de Brasília, Brasília, 2013. INSTITUTO BRASILEIRO DE GEOGRAFIA E ESTATÍSTICA (IBGE). Características Gerais dos 
Indígenas: resultados do universo, Censo demográfico 2010. Rio de Janeiro, 2012. 244 p. Disponível em: http://biblioteca.ibge.gov.br/visualizacao/periodicos/95/cd_2010_ indigenas_universo.pdf. Acesso em: 15 maio 2016.

MAZZETI, Camila Medeiros da Silva. Estado nutricional dos indígenas Pataxó de 5 aldeias de Minas Gerais, Brasil. 2015. 104p. Dissertação (Mestrado em Enfermagem) - Escola de Enfermagem e Nutrição, Universidade Federal de Minas Gerais, Belo Horizonte, 2015.

PENA, João Luiz; HELLER, Léo. Saneamento e saúde indígena: uma avaliação na população Xakriabá, Minas Gerais. Engenharia Sanitária e Ambiental, Rio de Janeiro, v. 13 n. 1, p. 63-72, jan./mar. 2008.

ROCHA, Tatiane Evangelista Silva; SILVA, Reijane Pinheiro da; NASCIMENTO, Maira Messias. Mudanças dos hábitos alimentares entre os Akwen Xerente. Revista da Escola de Enfermagem da USP [on-line], São Paulo, v. 50, número especial, p. 93-7, 2016. Disponível em: www.scielo.br/pdf/reeusp/v50nspe/0080-6234-reeusp-50-esp-0096.pdf. Acesso em: 21 nov. 2017.

SIMÕES, Bárbara dos Santos; MACHADO-COELHO, George Luiz Lins; PENA, João Luiz; FREITAS, Silvia Nascimento de. Condições ambientais e prevalência de infecção parasitária em indígenas Xukuru-Kariri, Caldas, Brasil. Revista Panamericana de Salud Publica, v. 38, n. 1, p. 42-8. 2015.

TOLEDO, Renata Ferraz de. Educação, saúde e meio ambiente: uma pesquisa-ação no Distrito de lauaretê do Município de São Gabriel da Cachoeira/AM. 2006. Tese (Doutorado em Saúde Pública) - Faculdade de Saúde Pública, Universidade de São Paulo, São Paulo, 2006.

\section{Sobre as autoras:}

Reijane Pinheiro da Silva: Doutora em Antropologia Social pela Universidade Federal do Rio Grande do Sul (UFRGS). Mestre em Sociologia e bacharel em Ciências Sociais pela Universidade Federal de Goiás (UFG). Professora do curso de Nutrição e do Programa de Pós-Graduação em Desenvolvimento Regional da Universidade Federal de Tocantins (UFT). E-mail: reipinheiro@gmail.com, Orcid: http://orcid.org/0000-0002-0636-9795

Denise Gomes Dourado: Mestre em Desenvolvimento Regional na Universidade Federal do Tocantins (UFT). Especialista em Gerenciamento Ambiental pela Universidade Católica do Salvador (UCSal). Graduada em Engenharia Sanitária 
e Ambiental pela Universidade Federal do Recôncavo da Bahia (UFRB). E-mail: denise.esa@gmail.com Orcid: http://orcid.org/0000-0002-9869-0286

Recebido em 8 de fevereiro de 2018

Aprovado para publicação em 20 de março de 2019 